\title{
LITIGÂNCIA CLIMÁTICA: A LEGITIMIDADE PROCESSUAL DOS MOVIMENTOS SOCIAIS AMBIENTAIS NA DISCUSSÃO CLIMÁTICA NO BRASIL
}

\section{RESUMO}

\author{
Andrea Almeida de Leite Marocco ${ }^{1}$ \\ Cristiani Fontanela ${ }^{2}$ \\ Guilherme de Oliveira Matos ${ }^{3}$
}

O presente artigo visa demonstrar como os movimentos sociais organizados podem se tornar litigantes legitimados para a proposição de demandas, buscando o respeito aos acordos internacionais climáticos, atualizados pela necessária formação e a respectiva contextualização dos interesses de agir para a proposição de demandas. Para tanto, a presente pesquisa se utiliza da metodologia de forma dedutiva respaldada em pesquisas bibliográficas que analisam historicamente os movimentos sociais e a nova corrente de litígios na esfera ambiental voltado à questão climática.

Palavras-chave: Mudanças climáticas. Movimentos sociais. Acordos climáticos. Litigios Climáticos. Legitimidade Processual.

\section{CLIMATE LITIGATION: THE PROCESSUAL LEGITIMACY OF SOCIAL ENVIRONMENTAL MOVEMENTS IN CLIMATE DISCUSSION IN BRAZIL}

\begin{abstract}
This article aims to demonstrate how organized social movements can become legitimate litigants for the proposition of demands, seeking respect for international climate agreements, updated by the necessary training and the respective contextualization of the interests of acting for the proposition of demands. Therefore, this research uses the methodology in a deductive way supported by bibliographical research that historically analyze the social movements and the new current of litigation in the environmental sphere focused on the climate issue.
\end{abstract}

Keywords: Climate change. Social movements. Climate agreements. Climatic litigation. Procedural Legitimacy.

\footnotetext{
${ }^{1}$ Doutorado em Curso de Pós-Graduação em Direito- Mestrado e Doutorado pela Universidade Federal de Santa Catarina, Brasil(2016) PROFESSORA da Universidade Comunitária da Região de Chapecó , Brasil

${ }^{2}$ Doutora e Mestre em Direito pela Universidade Federal de Santa Catarina - UFSC. Docente do programa de Mestrado em Direito e coordenadora do Núcleo de Inovação e Transferência Tecnológica - NITT da UNOCHAPECÓ. Advogada, inscrita na OAB/SC sob o nº 20806. Pesquisadora dos Grupos de Pesquisa Direito, Democracia e Participação Cidadã. - UNOCHAPECO e Liberdade, Estado e Desenvolvimento -LED da UNOCHAPECÓ. Possui experiência na área de propriedade intelectual, transferência de tecnologia e inovação.

${ }^{3}$ Graduação em Direito pela Universidade do Vale do Itajaí (2009). Tem experiência na área de Direito, com ênfase em Direito Tributário. Pós-graduado em Direito Tributário pelo Instituto Brasileiro de Estudos Tributários - IBET (2011). Pós-graduado em Direito Civil e Processo Civil pela Universidade Comunitária da Região de Chapecó - UNOCHAPECÓ (2014). Advogado. Professor Unochapecó. Mestrando em Direito na Unochapecó
} 


\section{INTRODUÇÃO}

As mudanças climáticas passaram a ser consideradas uma realidade do campo científico, sendo que para a esmagadora maioria dos cientistas ligados ao clima, é inequívoco que o aumento da temperatura possui ligação direta com causas antrópicas.

Ano após ano o IPCC ${ }^{4}$ vem traçando relatórios e compartilhando informações sobre as gravidades do aumento da temperatura média do planeta e também da relação entre homem e clima.

A relação entre a energia utilizada atualmente pelo homem tem sido considerada a maior inimiga em relação à poluição humana, tanto que, nesse contexto, destaca-se que a dependência da energia dos derivados de petróleo - gás e carvão - aos modelos de combustíveis fósseis resultam em aumento dos gases do efeito estufa.

Evidente que existem opiniões divergentes sobre a causa do aumento da temperatura média do planeta, sendo que uma diminuta parcela da comunidade científica atribui ao ciclo geológico as mudanças climáticas.

Uma vez admitido que a causa das mudanças climáticas estaria ligada à atividade humana, compreendeu-se a necessidade de que os Estados atuassem de forma conjunta para diminuir a emissão de gases causadores do efeito estufa.

Merecem destaque neste caminho os acordos da Rio 92, o Tratado de Kyoto em 1997 e especialmente o Acordo de Paris no ano de 2015. Em síntese, todos os acordos globais do clima sempre buscam diminuir essa dependência da matriz energética conhecida, além, obviamente, de tentar frear a emissão de gases que provocam o efeito estufa. Ainda em destaque, o Acordo de Paris merece o reconhecimento por sua forte adesão mundial e especialmente a voluntariedade com que os Países membros fixam suas metas e contribuições para a redução da emissão de gases que causam o efeito estufa.

Ganha campo a possibilidade então de que em um futuro não tão distante, interesses dicotômicos entre pretensos moradores da terra necessitem de buscar junto ao Poder Judiciário a devida responsabilização de atividades nocivas ao clima do planeta.

No Brasil, que possui uma multiplicidade de possibilidades jurídicas de litígio e de personificação, pode-se reconhecer que os movimentos sociais estão calcados na busca de

\footnotetext{
${ }^{4}$ Painel Intergovernamental sobre Mudanças Climáticas (Intergovernmental Panel on Climate Change). Trata-se de uma organização científico-política criada em 1988 no âmbito das Nações Unidas.
} 
interesse coletivo, especialmente relacionados à falta de percepção estatal sobre determinado assunto, buscando assim legitimar e requerer direitos perante o Poder Público.

A redemocratização do Estado Brasileiro, com o advento da Constituição da República Federativa do Brasil de 1988, tornou-se um celeiro de possibilidades jurídicas e processuais aos movimentos sociais organizados. Por outro vértice, aumentam constantemente os debates de preocupação com o clima do planeta e a natural consequência do aquecimento global decorrente em fonte majoritariamente científica que detenha relação com o aumento da emissão dos gases resultantes da queima de combustíveis fósseis.

Não se está aqui instigando a propagação de demandas, mas reconhecendo que o multifacetário processual brasileiro, tanto do texto constitucional quanto da legislação infraconstitucional, é farto ao reconhecer pela ampla possibilidade de ações que lastreiam a condição de defesa do interesse social difuso e coletivo.

A tal ponto a análise do movimento verde, social, e devidamente organizado ganha forte espaço na questão ambiental de discussão e delimitação da governança climática em busca de atitudes e posturas ambientais na especial proteção ao clima e as suas consequências.

Destarte, vislumbra-se que os movimentos sociais organizados deverão encontrar junto ao poder judiciário medidas, ditames e demandas processuais que irão combater atitudes, que causem aumento do efeito estufa, seja pelo setor privado, seja contra posturas do próprio poder público.

O presente artigo tem como objetivo discorrer acerca da possibilidade de judicialização de demandas que visem evitar atitudes geradoras do aumento dos gases causadores do efeito estufa. Promove uma abordagem voltada ao reconhecimento dos movimentos sociais ambientais e sua organização no Brasil, expondo situações sobre litigância e governança climática, bem como as oportunidades processuais no movimento ambiental climático, contextualizando a organização necessária que conduzirá o fenômeno da legitimidade e do interesse processual, condições básicas a serem referenciadas no arcabouço processual brasileiro que geram a aptidão à proposição de demandas com tal ponto.

Para tanto, neste artigo foi realizada uma pesquisa baseada na análise documental com revisão da literatura e da legislação relacionada, utilizando-se do método dedutivo para apresentar uma reflexão acerca da legitimidade dos movimentos sociais ambientais na discussão climática no Brasil. 


\section{MOVIMENTOS SOCIAIS AMBIENTAIS E SUA ORGANIZAÇÃO NO BRASIL}

O movimento social está atrelado especialmente à falta de respostas estatais diante de interesses de grupos coletivos. Para Gohn (1995, p. 44), os movimentos sociais são "ações coletivas de caráter sociopolítico, construídas por atores pertencentes a diferentes classes sociais que politizam suas demandas e criam um campo político de força social na sociedade civil". Ainda, segundo a autora, os movimentos sociais referem-se à ação dos homens na história. Esta ação envolve um fazer, caracterizado por meio de um conjunto de práticas sociais, e um pensar, através de um conjunto de ideais que motiva ou dá fundamento à ação (GOHN, 2000, p. 12).

Os movimentos sociais se caracterizam como ações coletivas que visam a promoção de mudanças políticas e sociais mais amplas, que produzem transformações na sociedade por meio de lutas e enfrentamentos coletivos em vários campos (SANTOS; FARIAS; ANDION, 2021).

O primeiro movimento socioambiental brasileiro foi representado pela Associação Gaúcha de Proteção ao Ambiente Natural - AGAPAN, que buscava a proteção ambiental em defesa da fauna e da vegetação.

Posteriormente à criação da AGAPAN outras associações foram criadas especialmente visando à denúncia de atos de degradação ambiental em ambientes rurais e urbanos (VIOLA, 2016, p. 8).

A noção de 'movimento ambientalista' tem sido evocada, no Brasil, para designar um espaço social de circulação de discursos e práticas associados à 'proteção ambiental', configurando uma nebulosa associativa formada por um conjunto diversificado de organizações com diferentes graus de estruturação formal, desde ONG e representações de entidades ambientalistas internacionais a seções 'ambientais' de organizações não especificamente 'ambientais' e grupos de base com existência associada a conjunturas específicas. (ACSELRAD, 2010, s.p.)

Ressalta-se que o movimento verde teve acepção em todo o mundo, em parte ligado à política de esquerda, reconhecendo os verdes como os vermelhos repaginados em relação à dicção política, inclusive com a proliferação de partidos verdes por todo o mundo (GIDDENS, 2010, p. 73-74).

Em que pese toda a dicção política dada ao tema, Giddens (2009) reconhece que diante dos interesses econômicos e os riscos sociais que se revelam através das mudanças 
climáticas a questão ambiental deixa de ter lado político e passa a ser uma preocupação comum, de efetiva governança pelo poder público em qualquer visão de opinião política:

\begin{abstract}
O movimento verde deixa como legado alguns dilemas centrais. Em que sentido, se é que há algum, lidar com a mudança climática e com a segurança energética significa que o crescimento econômico, como em geral compreendido, está inevitavelmente comprometido? Será que a vida política nos países industrializados, e talvez também noutros lugares, pode e deve ser remodelada para fazer com que o bem-estar substitua a riqueza como aspiração central do desenvolvimento? Também precisamos perguntar que utilidade têm os conceitos que provieram, ao menos em parte, do movimento verde. Em especial, eles incluem o princípio da precaução, a sustentabilidade e o princípio do 'poluidor pagador'. Uma das consequências da antipatia dos verdes pela política ortodoxa é que nos falta um conjunto de conceitos pertinentes à análise de como a política da mudança climática pode ser efetivamente integrada à prática política ortodoxa. (GIDDENS, 2010, p. 81).
\end{abstract}

Os movimentos sociais brasileiros, independentemente de lado político que possa ser tentado dar a roupagem, a bem da verdade, encontram possibilidades e pretensões que merecem ser reconhecidas.

A preocupação comum com o ambiente climático demonstra uma crescente corrente ao movimento social ambiental, especialmente em busca da proteção e controle da emissão dos gases causadores do efeito estufa.

A prova corrente do crescimento dos movimentos sociais, e de seu importante reconhecimento, está na própria atuação paritária dos conselhos do clima que compõem a Lei de Políticas Nacionais de Mudanças Climáticas (Lei 12.187/2009) que detém diversos conselhos criados 5 .

Nestes conselhos, por diversas ocasiões, se prevê a existência de membros ligados à sociedade civil organizada e a regulação paritária destes órgãos para definir políticas públicas relacionadas ao clima.

Tanto que o reconhecimento da atuação da sociedade civil organizada em prol do movimento ambiental é destacada por Adams:

\footnotetext{
5 Art. $7^{\circ}$ Os instrumentos institucionais para a atuação da Política Nacional de Mudança do Clima incluem:

I - o Comitê Interministerial sobre Mudança do Clima;

II - a Comissão Interministerial de Mudança Global do Clima;

III - o Fórum Brasileiro de Mudança do Clima;

IV - a Rede Brasileira de Pesquisas sobre Mudanças Climáticas Globais - Rede Clima;

V - a Comissão de Coordenação das Atividades de Meteorologia, Climatologia e Hidrologia.
} 
Todo esse processo gerou um estímulo crescente à participação da sociedade civil em várias instâncias de tomada de decisão, que se consolidou mais fortemente a partir dos anos 2000, com políticas públicas que fortaleceram também o poder de ação nos municípios. Assim, o reconhecimento da capacidade do fazer político e de intervir na ação pública pode ser experimentado pela população, tanto em lutas organizadas por movimentos sociais, como pela experiência de participação social. Isto levou a processos de aprendizagem valiosos e trouxe o envolvimento de uma multiplicidade de atores na formulação, implementação, avaliação e no controle social de políticas públicas. Decorrente desse processo, foram criados, por exemplo, mais de 20 mil conselhos no país, em âmbito federal, estadual e municipal, e foram realizadas, a partir de 2003, mais de cem Conferências Nacionais. (ADAMS et. al, 2020, p. 9).

Após a Revolução Industrial e início das medições, um ano após o outro é atestado o aumento significativo da temperatura média do planeta, bem como são vislumbradas suas consequências, como alterações no ciclo hidrológico, derretimento de geleiras continentais, redução de gelo no Ártico, aumento do nível do mar, entre outros (RODRIGUES, 2019, p. 43).

Visando a comprovar que a relação da atividade humana tem nexo com o aumento da temperatura média do planeta surgiu na década de 1980, "Para organizar as pesquisas climáticas e apresentar mais segurança nas informações, a Organização Meteorológica Mundial e o Programa das Nações Unidas para o Meio Ambiente criaram o Painel Intergovernamental sobre Mudanças Climáticas (Intergovernmental Panel on Climate Change - IPCC) (CARVALHO et. al, 2019. p. 59).

Com esta organização civil há a possibilidade de influenciar não somente na parte de litigância, que será adiante tratada, mas também em decisões administrativas que são tomadas pelo poder público em prol da existência de um modelo de governança climática.

Em síntese, conforme será adiante debatido, o movimento social ambiental encontra na democracia brasileira um campo fértil de proposição e posturas que levam a resultados reais de suas pretensões.

\section{A LITIGÂNCIA E A GOVERNANÇA CLIMÁTICA}

Entre as diversas preocupações globais ambientais, um dos pontos mais debatidos e de crescente preocupação têm sido as posturas ambientais climáticas e o devido controle da 
temperatura média global do planeta. Essa atenção se deve em razão justamente dos propensos resultados informados pelo Painel Intergovernamental sobre Mudanças Climáticas (INPCC), que traduz em seus relatórios uma crescente condição de riscos socioambientais caso não se consiga frear o aquecimento global, visando, especialmente, os anos de 2030 e 2050.

Em síntese, pelas análises científicas entende-se que os gases que provocam o efeito estufa detêm uma estreita relação com o início da Revolução Industrial e, assim, desde 1750, o planeta vem constantemente ficando mais quente (RODRIGUES, 2019, p. 43).

Ante a esta preocupação a ONU vem realizando estudos e acompanhamentos em relação ao clima do planeta e suas consequências, gerando, inclusive, em suas metas a proposição de atitudes governamentais que fomentem a modificação da matriz energética, hoje considerada a maior vilã no cenário de emissão de gases causadores do efeito estufa, o que resultaria no controle da temperatura do planeta.

Para tanto, merecem destaque três acordos internacionais do clima - não sendo estes os únicos - porém, os de maior relevância para a contextualização do problema climático global.

O primeiro desses acordos ocorreu na Rio 92, quando os países reunidos passaram efetivamente a discutir o clima do planeta e a modificação de posturas globais para a redução do clima planetário.

O segundo desses acordos ocorreu em Kyoto 97, em que os países se dividiram entre desenvolvidos e em desenvolvimento, criando proporcionalidades em suas atitudes de redução de emissão de gases de efeito estufa, além disso, o protocolo de Kyoto também criou um mercado de carbono, visando que a realização e manutenção de atitudes ambientais tivessem êxito através da indústria.

Ante aos insucessos das propostas, no ano de 2015 insurge o Acordo de Paris, uma efetiva revolução nas visões climáticas, eis que, através de uma constante análise das condições climáticas, os países que aderem ao Acordo podem optar por quais medidas, voluntariamente, irão realizar para reduzir as suas emissões de gases de efeito estufa, criando, assim, as suas Contribuições Nacionalmente Determinadas (CND) as quais com o cumprimento e reanálise podem conseguir atingir os objetivos e reduções propostos. 
Paralelo ao debate ambiental sobre o clima há a crescente preocupação do movimento socioambiental, que agora passa a ter uma preocupação conjunta em escala global, visando, obviamente, o posicionamento em prol da defesa do meio ambiente.

A postura socioambiental brasileira permite, em diversos momentos, o reposicionamento e a participação democrática em prol da exigência e implementação de políticas públicas ambientais, o que assim se reconhece:

Os mecanismos de participação social desenvolvidos no período de redemocratização no Brasil representaram avanços significativos, chegando a ser utilizados como princípio político-administrativo e forma de gestão pública progressista. Muitas experiências incluíram a participação popular em diversos âmbitos de governo e fomentaram a aprendizagem da sociedade civil em coproduzir políticas públicas (ver Yamamoto et al. neste volume), possibilitando, dessa maneira, a criação de novas institucionalidades socialmente mais inclusivas. Desde o fim do governo militar (1964-1985), a democracia brasileira caracterizou-se pela presença marcante de movimentos sociais em um padrão de funcionamento inovador de mobilização popular e, ao mesmo tempo, pela conquista de espaços de participação social em conselhos, comitês, órgãos públicos e espaços de consultas e deliberação. (ADAMS et. al, 2020, p. 8).

Entende-se que a governança climática passa a ser afetada também pela posição e postura assumida pelos movimentos sociais ambientais, que, naturalmente, passam a opinar, fiscalizar e auxiliar na formação das políticas públicas a serem implementadas a nível governamental.

Evidente que diante da democracia brasileira, se de um lado temos a governança, do outro, temos a possibilidade de litígios judiciais que podem levar a posturas e cobranças de atitudes governamentais em prol da redução de emissão de gases de efeito estufa e, consequentemente, a favor do clima no planeta.

O termo litigância climática encontra-se coligado a todo e qualquer litígio, judicial ou administrativo, em qualquer espécie de jurisdição que permita a discussão sobre fatos ou normas jurídicas que resultem em impactos climáticos.

Em referendado conceito de forma ampla, pode-se considerar a presença de litigância climática em qualquer forma de demanda que acarrete modificações e intenções climáticas e especialmente em resultados que podem ser contra ou a favor da melhora das condições climáticas de um determinado local.

Na visão de Gabriel Wedy, a litigância climática perpassa por cinco tendências e objetivos: 1) buscar com que governos cumpram os seus compromissos; 2) identificar nexo de 
causalidade entre conduta de extrativismo e o resultado climático do outro; 3) verificação de causalidade no aumento das emissões de gases e nas mudanças regionais do clima; 4) cobrar posturas por falhas omissivas ou comissivas governamentais; 5) a admissão de litígios de natureza climática através de elementos de controvérsia, interesse, obrigações e legitimidade (WEDY, 2019, p. 90).

Entende-se que o Brasil é um grande celeiro de possibilidades de proposições climáticas justamente pela participação democrática e social prevista no texto constitucional e na legislação infraconstitucional, que permite ao movimento ambiental a possibilidade desta litigância, como será adiante debatido.

\section{AS OPORTUNIDADES PROCESSUAIS DO MOVIMENTO AMBIENTAL CLIMÁTICO}

A proposição de uma demanda perpassa pelos requisitos de interesse e legitimidade ${ }^{6}$, os quais integram as condições de ação prevista no artigo 17 do Código de Processo Civil ${ }^{7}$.

Nessa análise, o interesse de agir nas demandas de interesse difuso e coletivo estão adstritos a uma contextualização de interesses e vontades, os quais, organizados, permitem a pretensão ao direito tutelado.

Não custa relembrar que não compete a terceiro pleitear direito alheio, com fundamento no artigo 18 do Código de Processo Civil, porém, o pluralismo processual brasileiro permite a devida organização social a defender o interesse coletivo.

Antes que se confunda a hipótese de interesse processual, deve-se perceber que a soma dos interesses individuais em busca de um mesmo sentido ou resultado forma o denominado interesse coletivo, como explicita Mancuso:

\footnotetext{
${ }^{6}$ De acordo com Didier Júnior (2018), "Processo pode ser compreendido como um modo de produção de norma jurídica. O processo jurisdicional, como espécie de processo, é também um meio de produção de norma jurídica. Sucede que ele não produz apenas a norma jurídica do caso concreto, como se costumava imaginar. O processo jurisdicional também serve como modo de produção da norma jurídica será construída a partir do exame de um caso concreto, que serve como padrão decisório para a solução de casos futuros semelhantes. $\mathrm{O}$ estudo do processo jurisdicional não pode prescindir desta constatação. A disciplina jurídica do processo deve sempre levar em conta que são dois os produtos normativos que podem advir de uma decisão judicial".

${ }^{7}$ Art. 17 Para postular em juízo é necessário ter interesse e legitimidade.
} 
Pode-se, assim, visualizar uma pirâmide, em modo de uma escala crescente de coletivização, em cuja base estão os interesses individuais, alguns desses interesses pertinem a pessoas que, por diversas razões, encontram-se em posições sociais bem definidas, tais as classes, as categorias, facilitando a aglutinação daqueles interesses nos grupos representativos dessas classes e categorias Esses interesses tornam-se então 'coletivos', e esses grupos vão representá-los. defendê-los e fomentá-los, como o fazem os sindicatos, as associações, as ordens e outras entidades do gênero. Num momento subsequente, verifica-se que alguns desses interesses coletivos depassam até mesmo a esfera de atuação de grupo e alcançam já a própria sociedade civil como um todo: passam a integrar interesse geral. Por exemplo, o interesse ao pleno emprego depassa a órbita dos sindicatos, o interesse à proteção da natureza como um todo extravasa o objeto estatutário das associações de proteção à ecologia, o interesse no desempenho equilibrado das relações de consumo é mais amplo do que o objetivado por um órgão de defesa de consumidores. (MANCUSO, 2019, p. 67).

Existem interesses naturais do grupo criado, o qual, inclusive, fundamenta a criação da pessoa jurídica, como associações, fundações, organizações e afins, detendo como seu próprio objetivo interpessoal dos seus adeptos a busca e a proteção de determinadas situações, e no, nosso caso, a proteção do meio ambiente.

Destarte, pode-se reconhecer que o interesse processual para a propositura das demandas está claramente contido na vontade individual que resulta em um interesse coletivo de resultados que podem ser eventualmente judicializados. Se de um lado temos por reconhecidos os interesses coletivos, de outro, temos a necessidade de perquirir a legitimidade processual destes atores coletivos e em quais espécies de demanda o resultado da litigância climática poderá ser alcançado pelos agentes que detêm o interesse apresentado.

O direito processual constitucional reconhece a legitimidade plural das entidades e da coletividade para a proteção do meio ambiente, e até mesmo para a proposição de demandas, visto que colhe-se no próprio texto constitucional as expressões de direito e dever, como se destaca no caput do artigo 225: "Todos têm direito ao meio ambiente ecologicamente equilibrado, bem de uso comum do povo e essencial à sadia qualidade de vida, impondo-se ao poder público e à coletividade o dever de defendê-lo e preservá-lo para as presentes e futuras gerações".

A rápida leitura do artigo 225 da Constituição permite a dicção de dever de proteção ao meio ambiente, tanto do aspecto do poder público quanto o dever da sociedade civil organizada em proteção ambiental. A própria responsabilização perante as próximas gerações já demonstra uma preocupação com a continuidade da vida humana no planeta e também com 
o reconhecimento de um momento de risco existencial impondo à geração atual um vínculo de obrigação com a geração futura (WEDY, 2019, p. 81).

Nesse sentido, compreende-se que, em algum momento, e em análise, à teoria processual brasileira poderiam os movimentos sociais ambientais, desde que tipicamente organizados, apresentar litígios em caráter climático, visto a presença do seu interesse e legitimidade, como demonstra-se no subtópico a seguir:

\section{a) A Ação Civil Pública Climática}

A ação civil pública está prevista na Lei n. ${ }^{0} 7.347 / 1985$ que com as modificações inseridas pela Lei n. ${ }^{\circ} 8.078 / 1990$, que reconheceu os interesses coletivos e difusos a serem recebidos por esse modelo processual.

A ação civil pública estaria com a legitimidade das instituições presentes ao passo que presente o requisito coletivo para a sua proposição, ou seja, teria que a associação ambiental assim respeitar o disposto no artigo $5^{\circ}$ da Lei $7.347 / 1985^{8}$, estando devidamente formada diante do que prospecta a lei civil e por sucessivo que esteja fundada há pelo menos um ano.

Já a proposição da demanda de ação civil pública em caráter climático pelas associações de direito ambiental poderia ter como objetivo de demanda, e aqui na dicção de mera exemplificação, as responsabilizações por danos morais e patrimoniais. Neste caso, a pretensão ficaria então voltada ao restabelecimento do equilíbrio ecológico exigindo a competente indenização ambiental e até mesmo como procedimento de tutela específica, como a abstenção de condutas ou até a reestruturação ambiental de áreas degradadas.

Ao exemplo de proposição, poderia se considerar a pretensão de abstenção de condutas de emissão de gases de efeito estufa de uma determinada empresa que estivesse descumprindo os seus planejamentos ambientais, exigindo assim a postura de readequação e indenização pela tutela equivalente (WEDY, 2019, p. 85).

\section{b) Mandado de Segurança Coletivo Climático}

\footnotetext{
8 Art. $5^{\mathrm{o}}$ Têm legitimidade para propor a ação principal e a ação cautelar: V - a associação que, concomitantemente:

a) esteja constituída há pelo menos 1 (um) ano nos termos da lei civil;

b) inclua, entre suas finalidades institucionais, a proteção ao patrimônio público e social, ao meio ambiente, ao consumidor, à ordem econômica, à livre concorrência, aos direitos de grupos raciais, étnicos ou religiosos ou ao patrimônio artístico, estético, histórico, turístico e paisagístico.
} 
O mandado de segurança, pelo interesse coletivo, poderá ser manejado por organizações, entidades ou associações, nos termos do disposto no artigo $21^{[5]}$ da Lei $12.016 / 2009^{9}$. A pretensão a ser buscada estaria diante do interesse coletivo na proteção ambiental ou ainda em direito difuso e homogêneo que viesse a ser afetado por um ato ilegal decorrente do poder público. Isso se deve ao fato que, em seara de mandado de segurança perfaz-se necessária contextualização de insurgência tida por ilegal que viola direito líquido e certo dessa coletividade aqui resistida.

Dessa maneira, acredita-se que o mandado de segurança coletivo de caráter climático poderia estar representado quando houver alguma liberação ambiental que contrarie o devido processo administrativo e legal e irá gerar consequências a mantença do clima, afetando, assim, sensivelmente a emissão de gases que provocam o efeito estufa.

\section{c) Mandado de Injunção Climático}

O mandado de injunção tem por característica a proposição de demanda que permite a total fruição dos direitos dos cidadãos previstos na Constituição Federal visando justamente a aplicação e a criação normativa de textos que não tenham sido tratados pelos órgãos competentes (MILARÉ, 2013, p. 1509).

A proposição aqui prevista fora regulamentada pela Lei 13.300/2016, que prevê a demanda, individual e coletiva, que busque a pretensão para a fruição de direitos ainda não regulamentados.

A este ponto a legitimidade processual coletiva encontra proximidade com aquela da regulação normativa da ação civil pública permitindo a associações que proponham a demanda ${ }^{10}$.

\footnotetext{
${ }^{9}$ Art. 21 O mandado de segurança coletivo pode ser impetrado por partido político com representação no Congresso Nacional, na defesa de seus interesses legítimos relativos a seus integrantes ou à finalidade partidária, ou por organização sindical, entidade de classe ou associação legalmente constituída e em funcionamento há, pelo menos, 1 (um) ano, em defesa de direitos líquidos e certos da totalidade, ou de parte, dos seus membros ou associados, na forma dos seus estatutos e desde que pertinentes às suas finalidades, dispensada, para tanto, autorização especial.

${ }^{10} \mathrm{O}$ mandado de injunção coletivo pode ser promovido:

[...] III - por organização sindical, entidade de classe ou associação legalmente constituída e em funcionamento há pelo menos 1 (um) ano, para assegurar o exercício de direitos, liberdades e prerrogativas em favor da totalidade ou de parte de seus membros ou associados, na forma de seus estatutos e desde que pertinentes a suas finalidades, dispensada, para tanto, autorização especial.
} 
Ao ponto que a falta de regulamentação de posturas climáticas por parte do Poder Público, poderia estar incluída em demandas injuntivas que exigiram as competentes regulações.

d) Proposições de demandas processuais civis

Não se pode deixar de excluir que a proposição normativa, pelo denominado rito de conhecimento, também estaria aqui abarcada na conduta normativa, e em que pese, muito mais voltado ao direito privado, poderia eventualmente estar exigindo-se por estes meios outros direitos climáticos. Uma vez reconhecida a legitimidade e o interesse delimitado no artigo 17 da Lei Processual Civil estar-se-ia diante da possibilidade de realização de requerimento a prestação jurisdicional competente.

Evidente que, nesse caso, o ente passivo estaria muito mais próximo, porém, não exclusivo, ao direito privado, em caráter reparatório e de abstenção a determinada conduta tida como poluidora e causadora de efeito climático diverso.

Dessa forma, restou demonstrado que por diversas formas a legislação processual brasileira permite a utilização de métodos processuais diversos e que fomentam a eventual proteção através de movimentos sociais organizados em buscar a litigância climática como forma de que seus interesses difusos possam ser reconhecidos e respeitados.

\section{CONCLUSÃO}

A análise realizada demonstrou a possibilidade de judicialização de demandas, de cunho processual em rito especial e procedimento comum que visam a inibir atitudes geradoras do aumento dos gases causadores do efeito estufa.

Fica evidente que a conduta coletiva processual estaria abarcada pelos conceitos de processo e litigância, permitindo, assim, que situações climáticas possam vir a ser defendidas por movimentos sociais organizados na forma da lei.

A processualística brasileira é terreno farto para a defesa dos interesses coletivos e difusos, permitindo o ingresso de pretensões climáticas pelos movimentos sociais, bem como pelo próprio cidadão legitimidade e organizado para tal pretensão. 
Os movimentos sociais ambientais têm tido um constante crescimento, em especial após o advento da Constituição da República Federativa do Brasil de 1988, quando reconhece-se e se dá legitimidade a associações para a proposição de demandas em caráter coletivo, desde que devidamente constituídas para tais fins.

Dessa forma, estreita-se que o novo desafio apresentado ao movimento social ambiental, devidamente organizado, está no palco de litígios climáticos que possuem um grandioso impacto global na luta pela manutenção da temperatura média do planeta.

Tal ponto decorre justamente diante dos tratados internacionais do clima e da busca de posturas que estejam voltadas a uma nova matriz energética que abandone a queima de combustíveis fósseis, além, obviamente, de posturas que busquem atitudes ambientais de diminuição da emissão de gases de efeito estufa.

Ante a tal pretensão, o embate e a processualística civil recorreram aos tradicionais pontos de interesse e legitimidade para tentar, assim, dar guarida aos atores legitimados em debater juridicamente as questões climáticas.

O multifacetário processual brasileiro permite que associações, especialmente com mais de um ano de fundação e objetivos específicos, sejam as efetivas representantes dos movimentos sociais ambientais em pelo menos, e não únicas, quatro espécies de demandas judiciais. Dessa forma, o que se observa é que a litigância climática poderá sim ser palco da atuação da sociedade civil organizada e assim contextualizada em meios processuais que estarão debatendo resultados e atuações tanto do poder público quanto do setor produtivo.

A medida de se reconhecer no Brasil estas legitimidades demonstra que o Estado não fica à mercê das suas previstas instituições, mas permite, com fulcro no permissivo do artigo 225 da Constituição da República Federativa do Brasil de 1988, que a sociedade realize, em determinadas situações, a atuação judicial em busca de resultados ambientais climáticos.

\section{REFERÊNCIAS}

ACSERLRAD, Henri. Ambientalização das lutas sociais - o caso do movimento por justiça ambiental. Estud. av., v. 24, n. 68, São Paulo, 2010. Disponível em:<

https://www.scielo.br/scielo.php?pid=S0103-

40142010000100010\&script=sci_arttext\&tlng=pt. > Acesso em: 10 mar. 2021.

ADAMS, Cristina Adams et al. Governança ambiental no Brasil: Acelerando em direção aos objetivos de desenvolvimento sustentável ou olhando pelo retrovisor? Repositório FGV de periódicos e revistas, Fórum Governança ambiental - Novos desafios na gestão, v. 25 n. 
81, maio/ago. 2020. Disponível em:

<http://bibliotecadigital.fgv.br/ojs/index.php/cgpc/article/view/81403>. Acesso em: 13 mar. 2021.

BRASIL. Constituição da República Federativa do Brasil [1988]. 3. ed. Rio de Janeiro: Saraiva, 2015.

CARVALHO. Délton Winter. Litigância Climática como Governança Ambiental, Revista Eletrônica da Esa/RS. Volume 3, Ano 3, p. 1-21. ESA - 2018.

CHALITA, Gabriel Benedito Issac. Democracia, Cooperação e Cidadania. Revista Jurídica Unicuritiba, Curitiba, v. 04, n. 57, p. 422-441, out./dez. 2019. Disponível em:

$<$ http://revista.unicuritiba.edu.br/index.php/RevJur/article/view/3780/371372138>. Acesso em: 13 mar. 2021.

DIDIER JÚNIOR, Fredie. Curso de direito processual civil. 18. ed. Salvador: Ed. JusPodivm, 2018.

GIDDENS, Anthony. A política da mudança climática: apresentação à edição brasileira Sérgio Besserman Vianna. Rio de Janeiro: Zahar, 2010.

GOHN, Maria da Glória. Movimentos e lutas sociais na história do Brasil. São Paulo: Loyola, 1995.

500 anos de lutas sociais no Brasil: movimentos sociais, ONGs e terceiro setor.

Revista de Ciências Sociais - Mediações, Londrina, v. 5, n.1, 2000.

MANCUSO, Rodolfo de Camargo. Ação civil pública: em defesa do meio ambiente, do patrimônio cultural e dos consumidores: Lei 7.347/1985 e legislação complementar. 12. ed. rev., atual. e ampl. São Paulo: Editora Revista dos Tribunais, 2011.

Interesses difusos: conceito e legitimação para agir. 9. ed. rev., atual. e ampl. São Paulo: Thomson Reuters Brasil, 2019.

MILARÉ. Édis. Direito do Ambiente. São Paulo: Editora RT, 2013.

RODRIGUES, Paulo Artaxo Délcio. As bases científicas das mudanças climáticas. In: VOGAS, Alice Amorim et al. (Coord.). Litigância climática: novas fronteiras para o direito ambiental no Brasil. São Paulo: Thomson Reuters Brasil, 2019.

SANTOS, Diego F; FARIAS, Regina M.; ANDION, Carolina. Os novos Movimentos Sociais: o caso do Movimento ODS Santa Catarina. Revista Grifos, Chapecó, v. 30, n. 52, maio/ago. 2021. Disponível em:<

https://bell.unochapeco.edu.br/revistas/index.php/grifos/index>. Acesso em: 14 mar. 2021.

VIOLA, Eduardo J. O movimento ecológico no Brasil (1974-1986): Do ambientalismo à ecopolítica. [s.1.], 2016. Disponível 
em: <https://acervo.socioambiental.org/sites/default/files/documents/S5D00005.pdf>. Acesso em: 13 mar. 2021.

VOGAS, Alice Amorim et al. (Coord). Litigância climática: novas fronteiras para o direito ambiental no Brasil. In: WEDY, Gabriel. A importância da litigância climática no Brasil. São Paulo: Thomson Reuters Brasil, 2019.

VOGAS, Alice de Moraes Amorim; LEITÃO, Sérgio. Litigância climática: novas fronteiras para o direito ambiental no Brasil. São Paulo: Thomson Reuters Brasil, 2019.

WEDY, Gabriel de Jesus Tedesco. Litígios Climáticos: de acordo com o Direito Brasileiro, Norte-Americano e Alemão. Salvador: Editora JusPodivm, 2019. 